\title{
Phantom Nodules Detected by Ultrasound Examination of the Neck: The Possibility of Ectopic Cervical Thymic Tissue in Adults
}

(ㄷ) (1) 오 $\odot$

\author{
Authors \\ Akira Miyauchi ${ }^{3}$ \\ Affiliations \\ 1 Kuma Hospital, Department of Clinical Laboratory, Kobe, \\ Japan \\ 2 Kuma Hospital, Department of Diagnostic Pathology and \\ Cytology, Kobe, Japan \\ 3 Kuma Hospital, Department of Surgery, Kobe, Japan
}

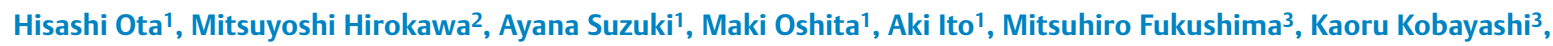

Key words:

ectopic thymus, involution, phantom nodule, speckled echo pattern, ultrasound

received 07.06 .2018

revised 05.09.2018

accepted 15.09.2018

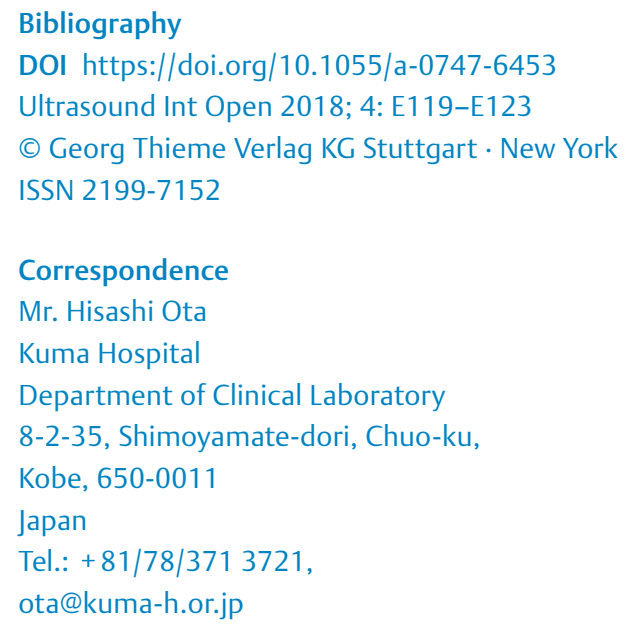

\section{ABSTRACT}

Purpose The aim of this study was to investigate the ultrasound characteristics and clinical significance of slightly hyperechoic lesions, referred to as phantom nodules, in the perithyroidal area in patients.

Materials and Methods A total of 128 patients who underwent thyroidectomy with central neck lymph node dissection at Kuma Hospital in Hyogo, Japan were included in the study. We detected 16 phantom nodules during preoperative ultrasound examinations, defined as slightly hyperechoic masses located in the perithyroidal areas, in 13 of these 128 patients (10.2\%; mean age: 55.6 years, range: $36-75$ years).

Results All phantom nodules were located in the caudal region of the thyroid gland, and the mean maximum dimension was $7.2 \mathrm{~mm}$. 12 of the 16 nodules were round or oval, while the remaining 4 were fusiform and molded by the surrounding tissue. All nodules were well-defined, solid, homogeneous, hyperechoic masses. No speckled echo pattern, internal linear echo, or vascular flow signal was observed. All 4 nodules subjected to histological examination were composed of ectopic thymic tissue. In 2 of these 4, the parenchyma was severely involuted and almost entirely replaced by adipose tissue.

Conclusion To the best of our knowledge, this is the first report wherein some of the detected hyperechoic perithyroidal masses were composed of ectopic thymic tissue, and some were primarily composed of adipose tissue that completely replaced involuted ectopic thymic tissue. The results of the study suggest that these so-called phantom nodules are clinically insignificant and do not require fine needle aspiration cytology or further investigation.

\section{Introduction}

Ultrasonography (US) is frequently used in a variety of clinical settings. With recent advances in technology, it has become possible to detect smaller and more obscure lesions using US. During thyroid US, clinicians may incidentally encounter small lesions in perithyroidal areas, such as aberrant thyroid tissue, parathyroid lesions, enlarged lymph nodes, certain types of cysts, thymic tissue, lipoma, nerve sheath tumor, and vascular malformation [1-6]. All of these lesions are generally hypoechoic or isoechoic [3-5]. However, we have occasionally encountered slightly hyperechoic lesions in the caudal area of the thyroid gland, although we have been unable to determine what they are, even via histological examination after thyroidectomy with central neck lymph node dissection. Accordingly, we refer to these lesions as phantom nodules. To the best of our knowledge, no study has investigated these phantom nodules. In the present study, we prospectively analyzed these phantom nodules detected via US in perithyroidal areas in adult patients and demonstrated that some of them consisted of ectopic thymic tissue (ETT). The aim of this study was to investigate the US characteristics and clinical significance of these slightly hyperechoic lesions. 


\section{Materials and Methods}

A total of 128 patients ( 106 female and 22 male, age range: $14-80$ years) who underwent thyroidectomy with central neck lymph node dissection at Kuma Hospital in Hyogo, Japan between January 2018 and March 2018 were included in the study. The 128 patients that underwent US examination in the study included 3 patients aged $<18$ years, and 125 patients aged $\geq 18$ years. Phantom nodules were defined as slightly hyperechoic masses located in perithyroidal areas. US was performed using the APLIO 500 TUS-A500 device (Toshiba Medical Systems Co., Ltd., Otawara, Japan) with a PLT805AT probe or a PLT-1005BT probe (both manufactured by Toshiba Medical Systems Co., Ltd.). During preoperative US examination, we detected 16 phantom nodules in 13/128 patients (10.2\%), and we analyzed the US characteristics of these 16 nodules. 5 of the 16 nodules were located outside the resected areas. 7 of the remaining 11 could not be confirmed, although the areas in which the nodules were present were resected. We subjected 4 resected nodules to histological analysis.

\section{Results}

The characteristics of the 16 nodules detected in 13 patients are summarized in $>$ Table 1 . The patients included 10 women and 3 men, with a mean age of 55.6 years (range: $36-75$ years). Relative to the entire study cohort, these patients did not demonstrate sex or age predilections. 10 patients exhibited 1 nodule, and 3 patients exhibited 2 . All of the nodules were located in the caudal region of the thyroid, in the right or left paratracheal region. There were no phantom nodules in the cranial region of the thyroid or in the lateral neck compartments. The mean maximum dimension was $7.2 \mathrm{~mm}$ (range: $5-13 \mathrm{~mm}$ ). Of the 16 nodules, 12 were round or oval ( $\triangleright$ Fig. 1 ) and 4 were fusiform and molded by the surrounding tissue (> Fig. 2). Two nodules were of a taller-than-wide shape, with a ratio of the anteroposterior diameter to the transverse diameter of $>1$ when measurements were made in the transverse plane. All nodules were well-defined, solid, homogeneous, hyperechoic lesions. No speckled echo pattern, internal linear echo, or vascular flow signal was observed.

After surgery, 4 nodules were subjected to histological examination. The remaining 12 ( 5 outside the resected areas and 7 within the resected areas) could not be evaluated. All 4 nodules that were histologically examined were determined to consist of ETT ( $\triangleright$ Fig. 3). In 2 of these 4, the parenchyma was severely involuted and almost entirely replaced by adipose tissue ( $\triangleright$ Fig. 4 ). The US characteristics of the phantom nodules confirmed to be ETT did not differ from those of the other nodules.

\section{Discussion}

In the present study, we analyzed the US characteristics and clinical significance of slightly hyperechoic lesions, referred to as phantom nodules, located in perithyroidal areas. The prevalence of the nodules was $10.2 \%$, and there was no sex predilection. The nodules were limited to the caudal region of the thyroid. On US, the nodules were characteristically well-defined, solid, homogeneous, hyperechoic, and hypovascular. There were no findings that indicated malignancy. 5 of the 16 detected nodules were located outside
- Table 1 Characteristics of the 16 phantom nodules detected by ultrasonography in the perithyroidal areas of 13 patients.

\begin{tabular}{|c|c|}
\hline Mean age in years (range) & $55.6(36-75)$ \\
\hline $\operatorname{Sex}(F / M)$ & $10 / 3$ \\
\hline Number (one/two) & $10 / 3$ \\
\hline Location in paratrachea (right/left) & $6 / 10$ \\
\hline Mean size $\#$ in mm (range) & $7.2(5-13)$ \\
\hline \multicolumn{2}{|l|}{ Ultrasound findings } \\
\hline \multicolumn{2}{|l|}{ Shape } \\
\hline Round or oval & 12 \\
\hline Fusiform (angulated or molding) & 4 \\
\hline Taller-than-wide ${ }^{\#}$ & 2 \\
\hline \multicolumn{2}{|l|}{ Margin } \\
\hline Well-defined/ill-defined & $16 / 0$ \\
\hline Hypoechoic/hyperechoic rim & $0 / 0$ \\
\hline \multicolumn{2}{|l|}{ Internal structure } \\
\hline Solid/cystic/focal cystic & $16 / 0 / 0$ \\
\hline Hyperechoic/isoechoic/hypoechoic & $16 / 0 / 0$ \\
\hline Homogeneous/heterogeneous & $16 / 0$ \\
\hline Speckled echo pattern & 0 \\
\hline Internal linear echoes & 0 \\
\hline \multicolumn{2}{|l|}{ Vascular flow signal } \\
\hline No/mild/moderate/severe & $16 / 0 / 0 / 0$ \\
\hline \multicolumn{2}{|l|}{ Histology } \\
\hline Ectopic thymic tissue & 4 \\
\hline Undetected & 12 \\
\hline \multicolumn{2}{|c|}{$\begin{array}{l}\# \text { \#reatest dimension; \#\# Ratio of the anteroposterior diameter to the } \\
\text { transverse diameter was }>1 \text { when measurements were performed in } \\
\text { the transverse plane. }\end{array}$} \\
\hline
\end{tabular}

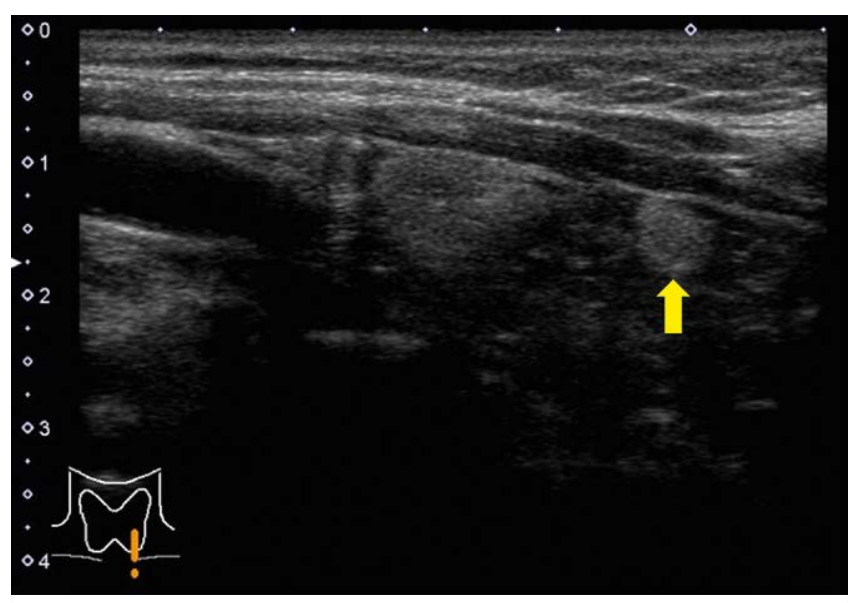

-Fig. 1 Ultrasound examination of a phantom hyperechoic nodule in the caudal region of the thyroid gland (arrow). It is round, slightly hyperechoic, and homogeneous (B-mode, longitudinal view).

the resected areas, and 7 of the remaining 11 could not be evaluated, although the areas in which they were present were resected. Thus, the nodules were typically "phantom." All 4 nodules that 


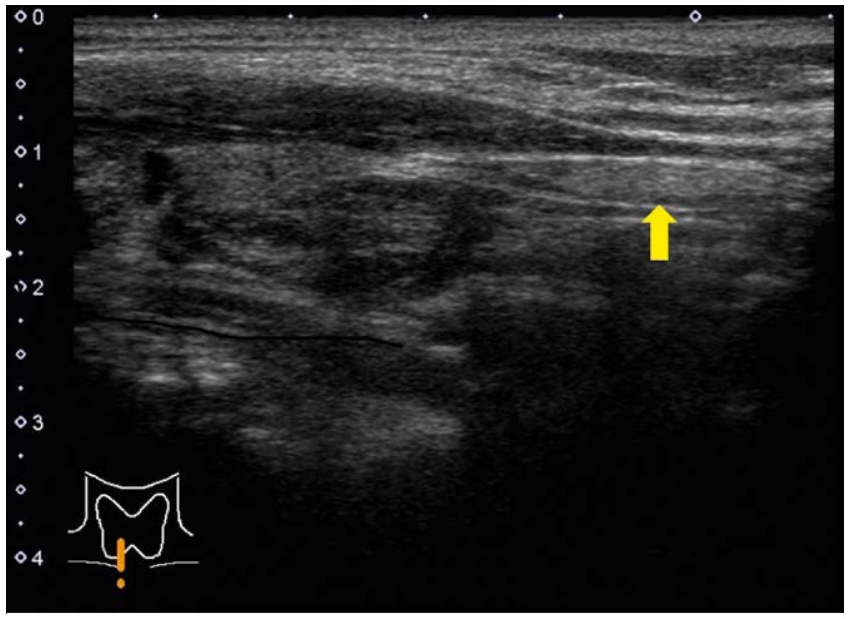

-Fig. 2 Ultrasound examination of a fusiform phantom hyperechoic nodule in the caudal region of the thyroid gland (arrow). It is molded by the surrounding tissue (B-mode, longitudinal view).

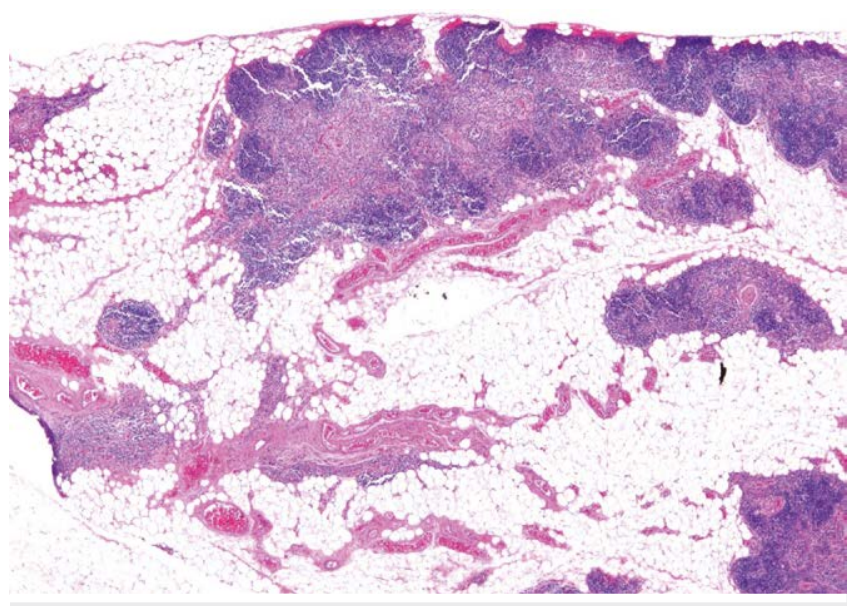

- Fig. 3 Histological examination of a mounted section of a phantom hyperechoic nodule resected from the thyroid gland (hematoxylin-eosin staining, $x 4$.) The tissue was confirmed to be ectopic thymic tissue composed of lymphoid cells, epithelial nests, and adipose tissue.

were histologically examined were composed of ETT. These results suggest that phantom nodules in perithyroidal areas are clinically insignificant and that further investigations such as fine needle aspiration cytology are not necessary.

When the thymus has not fully descended into the mediastinum, thymic tissue can be found in the neck [7-9]. Several authors have described the US characteristics of ETT [7-17]. According to their reports, the lesions are well-defined, angular, solid nodules with multiple inner echogenic foci and linear structures. The masses may be surrounded by hypoechoic rims. However, US examination of the four phantom nodules found to be ETT in the present study revealed them to be slightly hyperechoic, round, solid nodules without multiple inner echogenic foci or linear structures. Moreover, the aforementioned previous studies investigating ETT using US included children or infants, whereas the patients in which phantom nodules were detected in the present study were all adults. Physiologically, thymic tissue exhibits age-related involution

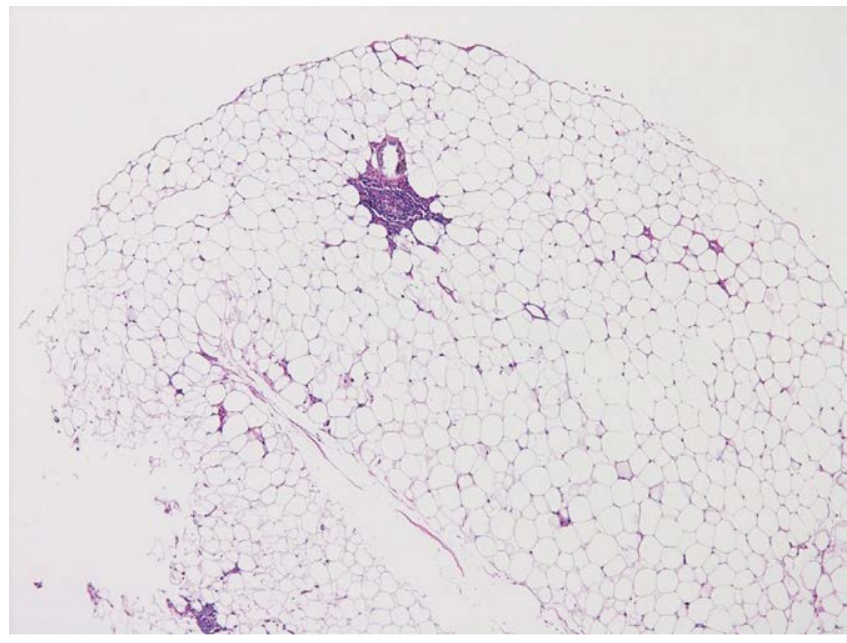

- Fig. 4 Histological examination of a mounted section of a phantom hyperechoic nodule resected from the thyroid gland (hematoxylin-eosin staining, $x 10$.) The tissue was confirmed to be ectopic thymic tissue. The parenchyma is severely involuted and almost entirely replaced by adipose tissue.

[18-20]. The reduction in thymic compartments leads to a reduction in size and replacement by adipose tissue [18-20]. Therefore, it can be assumed that the US characteristics of ETT change as a patient ages, and those observed in the present study do not represent thymic tissue observed in children or infants, rather they represent involuted thymic tissue in adults. Unfortunately, we could not perform histological analysis of 12 of the 16 detected phantom nodules. These could have been composed of adipose tissue that had replaced completely involuted ETT, given that their US characteristics and locations were similar to those of the nodules that were histologically confirmed to be ETT. Interestingly, the nodules confirmed to be ETT were limited to the caudal region of the thyroid. This probably explains why intrathyroidal thymic carcinoma, which is believed to originate from ETT, involves the lower pole of the thyroid $[21,22]$.

Differential diagnoses for small nodules located in the perithyroidal region include an enlarged parathyroid gland, lymph node, accessory thyroid nodule or ectopic thyroid tissue, carotid body paraganglioma, nerve sheath tumor, venous vascular malformation, and lipoma. Enlarged parathyroid glands due to adenoma, hyperplasia, or cysts are hypoechoic lesions [4, 23], as are lymph nodes [24-26]. The presence of an echogenic hilus and hilar vascularity on Doppler imaging assists in the identification of lymph nodes [26]. The echogenicity of accessory thyroid nodules or ectopic thyroid tissues, which exhibit vascular flow, is the same as that of the thyroid [27]. Carotid body paragangliomas are well-defined, solid, hypoechoic masses at a characteristic location, straddling the carotid bifurcation and splaying the internal and external carotid arteries [28]. Nerve sheath tumors are heterogeneously hypoechoic and often demonstrate posterior acoustic enhancement [5]. They are fusiform or ovoid with tapering ends, and continuity with adjacent nerves is a diagnostic feature [28]. Venous vascular malformations appear as soft, compressible, heterogeneous, hypoechoic masses [29]. They may contain multiple serpiginous sinusoidal spaces with vascular flow and phleboliths [30]. Lipomas are well-circumscribed, compressible, elliptical masses [31] that are usually 
slightly hyperechoic relative to the muscle echogenicity (75\%), though they can appear isoechoic or hypoechoic (25\%) [31]. No significant vascularity is present, and their characteristics are similar to those of ETT. However, the presence of multiple thin echogenic lines parallel to the transducer, resulting in a "feathered" or "striped" appearance, is characteristic [28]. Thus, we believe that it is not difficult to distinguish phantom nodules from the other small nodules located in the perithyroidal region.

Adenolipoma of the thyroid is a nodule composed of mature adipose tissue surrounded by a fibrous capsule, and it is associated with proliferation of thyroid follicles without cytologic atypia or capsular or vascular invasion. With the exception of location, its US characteristics including an ovoid shape, homogeneity, and hyperechogenicity [32] are similar to those of phantom nodules.

It has recently been reported that semiquantitative elastosonography is a valuable tool for the characterization of thyroid nodules, and it is reportedly more sensitive than contrast-enhanced US [33-35]. However, we did not perform semiquantitative elastosonography in the current study because this new technique is not yet commonly used in Japan. Thus, we did not have access to the required equipment. We expect that such techniques will yield more accurate characterization of the US features of phantom nodules in the future.

In conclusion, to the best of our knowledge, this is the first report describing the US characteristics of the hyperechoic lesions that are occasionally observed in perithyroidal areas, referred to as phantom nodules. The incidence of these phantom nodules was $10.2 \%$, and all were detected in adults. Some were histologically confirmed to be ETT, while the remaining may have been completely involuted ETT. The results of the study suggest that these phantom nodules are clinically insignificant and do not require fine needle aspiration cytology or any other further investigation. Moreover, it is not difficult to distinguish these phantom nodules from other small nodules located in the caudal region of the thyroid, with the exception of lipoma. Notably, the US features of ETT in children and adults may differ.

\section{Conflict of Interest}

The authors declare no conflict of interest.

\section{References}

[1] Patel SB, Shah SR, Goswami KG, Patel HB. Pictorial essays: Ultrasound features of thyroid and parathyroid lesions. Indian J Radiol Imaging 2005; 15: 211-216

[2] Ahuja A, Ying M. Sonographic evaluation of cervical lymph nodes. AJR Am J Roentgenol 2005; 184: 1691-1699

[3] Corroller TL, Sebag F, Vidal V, Jacquier A, Champsaur P, Bartoli JM, Moulin G. Sonographic diagnosis of a cervical vagal schwannoma. J Clin Ultrasound 2008; 37: 57-60

[4] Wieneke JA, Smith A. Parathyroid adenoma. Head Neck Pathol 2008; 2: $305-308$

[5] Reynolds DL Jr, Jacobson JA, Inampudi P, Jamadar DA, Ebrahim FS, Hayes CW. Sonographic characteristics of peripheral nerve sheath tumors. AJR Am J Roentgenol 2004; 182: 741-744
[6] Leboulleux S, Girard E, Rose M, Travagli JP, Sabbah N, Caillou B, Hartl DM, Lassau N, Baudin E, Schlumberger M. Ultrasound criteria of malignancy for cervical lymph nodes in patients followed up for differentiated thyroid cancer. J Clin Endocrinol Metab 2007; 92: 3590-3594

[7] Zielke AM, Swischuk LE, Hernandez JA. Ectopic cervical thymic tissue: Can imaging obviate biopsy and surgical removal? Pediatr Radiol 2007; 37: 1174-1177

[8] Ozel A, Akdur PO, Celebi I, Karasu R, Yilmaz B, Basak M. Ectopic cervical thymus as a rare cause of pediatric neck mass: The role of ultrasound and MRI in the diagnosis. Case report. Med Ultrason 2015: 17: $248-251$

[9] Meyer E, Mulwafu W, Fagan J], Brown RA, Taylor K. Ectopic thymic tissue presenting as a neck mass in children: a report of 3 cases. Ear Nose Throat J 2010; 89: 228-231

[10] Chu WCW, Metreweli C. Ectopic thymic tissue in the paediatric age group. Acta Radiologica 2002; 43: 144-146

[11] Fitoz S, Atasoy C, Türköz E, Gümüş D, Erden I, Akyar S. Sonographic findings in ectopic cervical thymus in an infant. J Clin Ultrasound 2001; 29: 523-526

[12] Erol OB, Şahin D, Bayramoğlu Z, Yılmaz R, Akpınar YE, Ünal ÖF, Yekeler E. Ectopic intrathyroidal thymus in children: Prevalence, imaging findings and evolution. Turk J Pediatr 2017; 59: 387-394

[13] Kabaalioğlu A, Öztek MA, Kesimal U, Çeken K, Durmaz E, Apaydın A. Intrathyroidal ectopic thymus in children: A sonographic survey. Med Ultrason 2017; 19: 179-184

[14] Fukushima T, Suzuki S, Ohira T, Shimura H, Midorikawa S, Ohtsuru A, Sakai A, Abe M, Yamashita S, Suzuki S.Thyroid Examination Unit of the Radiation Medical Center for the Fukushima Health Management Survey. Prevalence of ectopic intrathyroidal thymus in Japan: The Fukushima Health Management Survey. Thyroid 2015; 25: 534-537

[15] Ünal E, Düzkalır HG, Kurt-Güney S, Işıldak ET. Aberrant cervical thymus and the role of ultrasonography: A case report. Turk J Pediatr 2016; 58 : 230-231

[16] Yildiz AE, Elhan AH, Fitoz S. Prevalence and sonographic features of ectopic thyroidal thymus in children: A retrospective analysis. J Clin Ultrasound 2018; 46: 375-379

[17] Song I, Yoo SY, Kim JH, Hong E, Yoon HK. Aberrant cervical thymus: Imaging and clinical findings in 13 children. Clin Radiol 2011; 66: $38-42$

[18] Dixit VD. Thymic fatness and approaches to enhance thymopoietic fitness in aging. Curr Opin Immunol 2010; 22: 521-528

[19] Gui J, Mustachio LM, Su DM, Craig RW. Thymus size and age-related thymic involution: early programming, sexual dimorphism, progenitors and stroma. Aging Dis 2012; 3: 280-290

[20] Lepletier A, Chidgey AP, Savino W. Perspectives for improvement of the thymic microenvironment through manipulation of thymic epithelial cells: A mini review. Gerontology 2015; 61: 504-514

[21] Miyauchi A, Kuma K, Matsuzuka F, Matsubayashi S, Kobayashi A, Tamai H, Katayama S. Intrathyroidal epithelial thymoma: An entity distinct from squamous cell carcinoma of the thyroid. World J Surg 1985; 9: 128-135

[22] Hirokawa M, Miyauchi A, Minato H, Yokoyama S, Kuma S, Kojima M. Intrathyroidal epithelial thymoma/carcinoma showing thymus-like differentiation; Comparison with thymic lymphoepithelioma-like carcinoma and a possibility of development from a multipotential stem cell. APMIS 2013; 121: 523-530

[23] Abboud B, Sleilaty G, Rabaa L, Daher R, Abou Zeid H, Jabbour H, Hachem K, Smayra T. Ultrasonography: highly accuracy technique for preoperative localization of parathyroid adenoma. Laryngoscope 2008; 118: 1574-1578 
[24] Net JM, Mirpuri TM, Plaza M], Escobar CA, Whittington EE, ColladoMesa F, Yepes MM. Resident and fellow education feature: US evaluation of axillary lymph nodes. Radiographics 2014; 34: 1817-1818

[25] Ying M, Ahuja A, Brook F, Brown B, Metreweli C. Sonographic appearance and distribution of normal cervical lymph nodes in a Chinese population. J Ultrasound Med 1996; 15: 431-436

[26] Singh AK, Hegde P, Sakalecha AK, Suresh TN, Sreeramulu PN. Evaluation of cervical lymph nodes by ultrasonography in correlation with FNAC. J of Evolution of Med and Dent Sci 2015; 4: 1533-1551

[27] Ibrahim NA, Fadeyibi IO. Ectopic thyroid: Etiology, pathology and management. Hormones 2011; 10: 261-269

[28] Yuen HY, Ahuja AT. Benign clinical conditions in the adjacent neck. In: Sofferman RA, Ahuja AT. (eds.) Ultrasound of the Thyroid and Parathyroid Gland. New York: Springer; 2012: 229-262

[29] Demir B, Kantarci M, Sumbullu MA, Yuce I. Venous malformation between the external and internal jugular vein results in swelling: Multidetector computed tomography imaging. Eurasian J Med 2008; 40: $33-35$

[30] Chava VR, Shankar AN, Vemanna NS, Cholleti SK. Multiple venous malformations with phleboliths: radiological-pathological correlation. J Clin Imaging Sci 2013; 3: 13

[31] Ahuja AT, Lee YYP, Yuen HY. Lipoma. In: Ahuja AT. (ed.) Diagnostic Ultrasound: Head and Neck. Manitoba: Amirsys; 2014: 44-47
[32] Pennisi M, Conti A, Farina R, Foti PV, Cocuzza G, Boncoraglio A, Costanzo V, Costanzo G. Thyroid adenolipoma: A case report. J Ultrasound 2018; 21: 165-168

[33] Cantisani V, Consorti F, Guerrisi A, Guerrisi I, Ricci P, Di Segni M, Mancuso E, Scardella L, Milazzo F, D'Ambrosio F, Antonaci A. Prospective comparative evaluation of quantitative-elastosonography (Q-elastography) and contrast-enhanced ultrasound for the evaluation of thyroid nodules: Ppreliminary experience. Eur J Radiol 2013; 82: 1892-1898

[34] Sidhu PS, Cantisani V, Dietrich CF, Gilja OH, Saftoiu A, Bartels E, Bertolotto M, Calliada F, Clevert DA, Cosgrove D, Deganello A, D'Onofrio M, Drudi FM, Freeman S, Harvey C, Jenssen C, Jung EM, Klauser AS, Lassau N, Meloni MF, Leen E, Nicolau C, Nolsoe C, Piscaglia F, Prada F, Prosch H, Radzina M, Savelli L, Weskott HP, Wijkstra H. The EFSUMB guidelines and recommendations for the clinical practice of contrast-enhanced ultrasound (CEUS) in non-hepatic applications: Update 2017 (long version). Ultraschall Med 2018; 39: e2-e44

[35] Cantisani V, Grazhdani H, Drakonaki E, D'Andrea V, Di Segni M, Kaleshi E, Calliada F, Catalano C, Redler A, Brunese L, Drudi FM, Fumarola A, Carbotta G, Frattaroli F, Di Leo N, Ciccariello M, Caratozzolo M, D'Ambrosio F. Strain US elastography for the characterization of thyroid nodules: Advantages and limitation. Int J Endocrinol 2015; 2015: 908575 